\title{
Genetic Analysis of the APC Gene in Taiwanese Familial Adenomatous Polyposis
}

\author{
Shu-Chen Wei ${ }^{a}$ Yi-Ning Su ${ }^{b}$ Jyy-Jih Tsai-Wuc C.-H. Herbert Wu d,e \\ Jin-Chuan Sheu ${ }^{a}$ Cheng-Yi Wang ${ }^{a}$ Jau-Min Wong ${ }^{a}$
}

Departments of anternal Medicine, bMedical Genetics and cMedical Research, National Taiwan University Hospital and College of Medicine, Institute of Molecular Medicine, Medical College, National Taiwan University,

eAbGenomics Co., Taipei, 'Neuro-Medical Scientific Center, Buddhist Tzu Chi Medical Center, Hualien, Taiwan, ROC

\section{Key Words}

Denaturing high-performance liquid chromatography . Sequence $\cdot$ APC $\cdot$ Taiwan - Familial adenomatous polyposis

\begin{abstract}
Colorectal cancer has become the third leading cause of death from cancer in Taiwan. Familial adenomatous polyposis (FAP) is an autosomal dominant inherited disease characterized by the presence of multiple adenomatous polyps in the colon and rectum. The gene responsible for FAP (APC) was cloned in 1991. Extensive analyses of the mutation spectra in FAP kindreds have been performed in different countries, but the results have been highly variable $(30-80 \%)$. In this study, we used denaturing high-performance liquid chromatography (DHPLC) followed by automatic sequencing in an effort to establish the mutation spectrum of APC from DNA of peripheral blood cells. Among the 6 FAP probands analyzed, mutations were detected in $3(50 \%), 2$ of which were novel. The first novel mutation was at codon 2166 , with a $C$ to $T$ transition, resulting in a stop codon. The second novel mutation was at codon 1971, with a $C$ to $G$ transversion, resulting in an amino acid change from serine to cysteine. The third mutation involved an $A$ insertion in the sequence of -AAAAAA- at codons 1554-1556, which created a downstream stop codon (codon 1558). This
\end{abstract}

study is the first to report mutation analysis in Taiwanese FAP probands.

Copyright $\odot 2004$ National Science Council, ROC and S. Karger AG, Basel

\section{Introduction}

Colorectal cancer is one of the most common forms of neoplasm and the incidence is increasing in industrial countries [8]. Although currently colorectal cancer is not the leading cause of cancer mortality in Taiwan, it is noteworthy that the incidence of colorectal cancer has increased recently [14]. Analysis of the leading causes of death from cancer between 1987 and 2001 showed that colorectal cancer has become the third leading cause of cancer mortality in Taiwan. The annual mortality from this disease increased from 1,400 to 3,457 during the same period. Thus, colorectal cancer has become one of the most important diseases in Taiwan and is likely to continue to increase in prevalence.

In the past decade, a number of important discoveries have helped to elucidate the molecular mechanisms of tumorigenesis of colorectal cancers. These include findings regarding the involvement of activation of specific oncogenes, inactivation of tumor suppresser genes and inactivation of DNA repair systems. Familial adenomatous polyposis (FAP) and hereditary non-polyposis colorectal cancer are two well-characterized hereditary colo-

\begin{tabular}{ll}
\hline KARGER & S 2004 National Science Council, ROC \\
Fax + 41 61 3061234 & S. Karger AG, Basel \\
E-Mail karger@karger.ch & 1021-7770/04/0112-0260\$21.00/0 \\
www.karger.com & Accessible online at: \\
www.karger.com/jbs
\end{tabular}

Jaum-Min Wong, MD, PhD

Department of Internal Medicine, National Taiwan University Hospital

No. 7 Chung Shan South Road, Taipei, Taiwan (ROC)

Tel. +886223123456, ext. 5696, Fax +886223411171

E.Mail jmwong@ha.mc.ntu.edu.tw 
rectal cancers. FAP is an autosomal dominant inherited disease characterized by the presence of multiple adenomatous polyps in the colon and rectum. Affected individuals may develop as many as thousands of adenomatous polyps in the colon. The first polyps occur, on average, at age $15[27,28]$. If left untreated, cancer inevitably develops at a median age of 39 years [2]. FAP is also associated with extracolonic manifestations including desmoids, osteomas, epidermoid cysts, congenital hypertrophy of the retinal pigment epithelium and other tumors (brain, thyroid and liver) [11, 24]. APC, the gene responsible for FAP, was cloned in 1991 and was found to be located at chromosome $5 \mathrm{q}[3,12,18]$. The APC gene is a negative regulator of $\beta$-catenin and is considered to play a role as a gatekeeper in the adenoma-carcinoma sequence [1].

A small proportion of FAP patients have a cytogenetically visible interstitial deletion of the long arm of chromosome 5, while some of these patients have the entire APC gene removed $[15,21]$. However, the vast majority of FAP patients bear a genetic alteration involving mutations in either a single base pair or a small number of base pairs. Over 600 different germ line mutations in APC have been documented using different techniques [11, 31]. Subsequently, mutation spectra in FAP kindreds of different countries were established and showed highly variable results $(30-80 \%)$, suggesting variation among different ethnic groups $[5,6,11,17,19,24,25,29]$.

Thorough understanding of the molecular mechanisms will help to classify cases of hereditary colorectal cancer and to design optimal therapies. Individuals from families with a high risk of colorectal cancer (hereditary nonpolyposis colorectal cancer and FAP) should be offered genetic counseling, predictive molecular testing and, when indicated, endoscopic surveillance at appropriate intervals [13]. Likewise, chemoprevention can be prescribed for those with a diagnosis of hereditary colorectal cancer. Clinical surveillance and chemoprevention can be restricted to patients with germ line defects. In the present study, we conducted a mutation analysis of the APC gene in Taiwanese FAP kindreds in an effort to facilitate the possibility of taking such clinical measures.

\section{Patients and Methods}

\section{Patients}

This study included 6 probands from unrelated families registered at the National Taiwan University Hospital or Buddhist Tzu Chi Hualien General Hospital. Patients were referred to this study initially based on clinically suspicious colonoscopic findings, and the diagnosis of hereditary colon cancer was subsequently confirmed by surgery and/or suggestive family history of FAP, multiple polyps or colon cancer. An initial screening was performed on a single proband from each of the 6 unrelated families. Additional family members, when available, were tested for the segregation of specific molecular variants. After completion of a thorough genetic counseling session and signing of the informed consent form for participation in the study, a 20-ml blood sample was drawn in EDTA from each individual for the preparation of genomic DNA and RNA samples. To further clarify the identified changes as a polymorphism or mutation, population analysis with genomic DNA of 250 anonymous individuals from the DNA bank of the Department of Medical Genetics of the National Taiwan University Hospital was used as the population control.

\section{DNA Purification}

DNA was purified from $200 \mu$ of whole blood using the Viogene blood and tissue genomic DNA extraction kit (Viogene, Taipei, Taiwan) according to the manufacturer's instructions.

\section{PCR Conditions}

Polymerase chain reactions of $A P C$ exons were performed in a $50-\mu 1$ volume containing $10 \mathrm{mmol} / 1$ Tris- $\mathrm{HCl}, \mathrm{pH} 8.3,50 \mathrm{mmol} / 1$ $\mathrm{KCl}, 1.5-4.5 \mathrm{mmol} / 1 \mathrm{MgCl}_{2}, 50 \mathrm{mmol} / \mathrm{ldNTPs}$, a $0.25-\mathrm{mmol} / \mathrm{l} \mathrm{con-}$ centration of each primer, $100 \mathrm{ng}$ of genomic DNA and $1 \mathrm{U}$ of BioThermStar TM DNA polymerase (Gene Craft GmbH, Münster, Germany). The PCR cycling reaction was initiated with a 10 -min denaturation step at $95^{\circ} \mathrm{C}$ to activate BioThermStar DNA polymerase. Subsequent denaturing steps included $94^{\circ} \mathrm{C}$ for $20 \mathrm{~s}$ and an extension step of $72^{\circ} \mathrm{C}$ for $45 \mathrm{~s}$. For analysis of possible mutations within the promoter region and all exons including splicing sites of the APC gene, primers were designed to amplify the promoter region and each exon including the splicing acceptor and donor sequences. Primer pairs and the adjusted temperatures for individual amplicons are given in tables 1 and 2 .

\section{Denaturing High-Performance Liquid Chromatography}

Denaturing high-performance liquid chromatography (DHPLC) was carried out on automated HPLC instrumentation equipped with a DNASep column (Transgenomic Inc., San Jose, Calif., USA). The column was packed with proprietary 2-mm nonporous alkylated poly(styrenedivinylbenzene) beads [16]. The mobile phase was $0.1 \mathrm{M}$ triethylammonium acetate buffer, pH 7, containing $0.1 M$ EDTA. Crude PCR products were subjected to an additional denaturing step at $95^{\circ} \mathrm{C}$ for $3 \mathrm{~min}$ followed by a gradual reannealing step from 95 to $65^{\circ} \mathrm{C}$ over a period of $30 \mathrm{~min}$. The products were eluted with a linear acetonitrile (9017-03; J.T. Baker, Phillipsburg, N.J., USA) gradient at a flow rate of $0.9 \mathrm{ml} / \mathrm{min}$. The start and end points of the gradient were adjusted according to the size of the PCR products using an algorithm provided by WAVEmaker system control software (Transgenomic Inc.). Eight microliters of PCR product was injected for analysis in each run. Generally, analysis took about $10 \mathrm{~min}$ per injection, including column regeneration and reequilibration to the starting condition. The temperature required for successful resolution of heteroduplex molecules was determined with the DHPLC melting algorithm. Details about the temperature conditions and the algorithm itself were obtained using WAVEmaker software. The appropriate experimental conditions for performing DHPLC are listed in tables 2 and 3 . Heterozygous profiles were identified by visual inspection of the chromatograms on the basis of the appearance of additional earlier eluting peaks. Corresponding homozygous profiles showed only 1 peak. 
Table 1. Primers and conditions for DHPLC (promoters and exons 1-14)

\begin{tabular}{|c|c|c|c|c|c|c|}
\hline Amplicon & Forward primer $(5-3)$ & Reverse primer $\left(5^{\prime}-3^{\prime}\right)$ & $\begin{array}{l}\text { Size } \\
\text { bp }\end{array}$ & $\begin{array}{l}\text { Anneal- } \\
\text { ing, }{ }^{\circ} \mathrm{C}\end{array}$ & $\begin{array}{l}\text { DHPLC } \\
{ }^{\circ} \mathrm{C}\end{array}$ & Gradient $^{1}$ \\
\hline PROMOTER-A & CCCCCATTTAAACCAGAATTT & TCGATTGCTATGATTTTTGCAG & 541 & 58 & 54 & $59 \%$ B $4.5 \mathrm{~min}$ \\
\hline $\mathrm{APCe} 1$ & TTTCTTTAAAAACAAGCAGCCA & CACAGAAAACCTTGCCTCAG & 519 & 58 & 53 & $60 \%$ B $4.5 \mathrm{~min}$ \\
\hline $\mathrm{APCe} 2$ & AAGGTGCGTGCTTTGAGAGT & ACCAACACCCAAATCGAGAG & 308 & 58 & 54 & $57 \%$ B $4.5 \mathrm{~min}$ \\
\hline APCe3 & CCAAGTGGACTTTTCAGGGA & CTGGAGTACACAAGGCAATGTT & 412 & 58 & 53 & $57 \%$ B $4.5 \mathrm{~min}$ \\
\hline $\mathrm{APCe} 7$ & GCAGCTCTAATGCTCAAGGG & TGGTACTGAATGCTTCTGGAAA & 465 & 58 & 57 & $54 \%$ B $4.5 \mathrm{~min}$ \\
\hline $\mathrm{APCe} 8$ & CCATTCTGCAGTTTAATGCTCA & TAGAGATGGGGTTTTGCCAC & 512 & 58 & 53 & $60 \% \mathrm{~B} 4.5 \mathrm{~min}$ \\
\hline $\mathrm{APCe} 9$ & CTGGAAAGGTTTTCCGGTTT & TGCTTTGAAACATGCACTACG & 577 & 58 & 58 & $57 \%$ B $4.5 \mathrm{~min}$ \\
\hline $\mathrm{APCe} 10$ & GTCAAGGGCAGATGAGTGGT & TTCTATGCTGGAAACCAGGG & 511 & 58 & 54 & $59 \% \mathrm{~B} 4.5 \mathrm{~min}$ \\
\hline APCell & TTGTCTTTTTCCTCTTGCCC & AGCGAATGTGAAGCACAGGT & 362 & 58 & 54 & $57 \%$ B $4.5 \mathrm{~min}$ \\
\hline $\mathrm{APCe} 12$ & CCTGTTGCTTATCATTTCTCACC & AGAGTGAGACCCTGCCTCAA & 391 & 62 & 54 & $57 \% \mathrm{~B} 4.5 \mathrm{~min}$ \\
\hline
\end{tabular}

1 Eluent B: $0.1 \mathrm{M}$ triethylammonium acetate, $\mathrm{pH} 7.25, \%$ acetonitrile.

Table 2. Primers and conditions for DHPLC (exon 15)

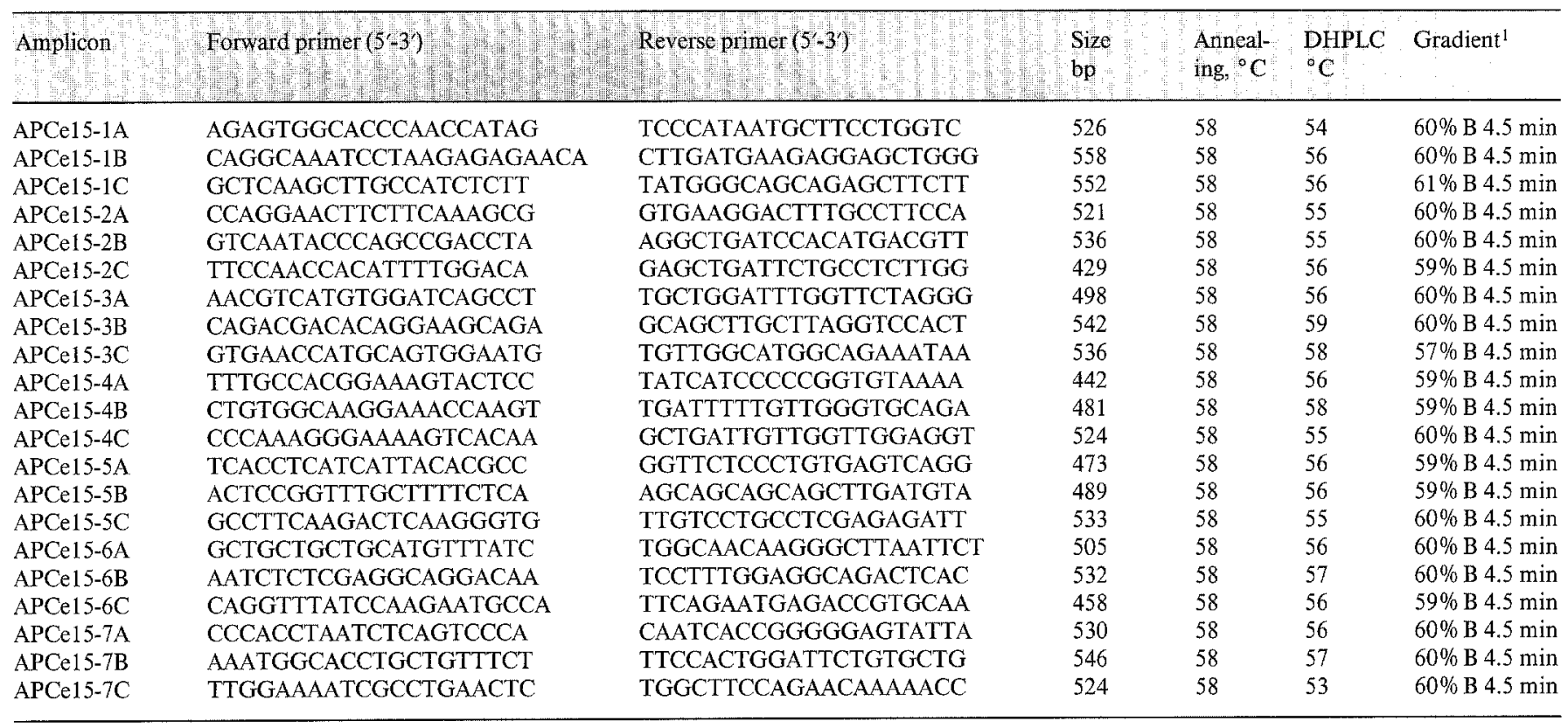

1 Eluent B: $0.1 M$ triethylammonium acetate, $\mathrm{pH} 7.25, \%$ acetonitrile.

\section{Direct Sequencing}

Sequencing reactions were performed for the samples that showed heterozygous profiles during DHPLC analysis using the ABI PRISM ${ }^{\mathrm{TM}}$ Dye Terminator Cycle Sequencing Ready Reaction kit (PE Applied Biosystems Inc., Foster City, Calif., USA). Electrophoresis was carried out using a Genetic Analyzer 310 (PE Applied Biosystems Inc.) equipped with long-read sequencing capillary and POP-6 sequencing polymer (PE Applied Biosystems Inc.). Primers used for direct sequencing reactions were the same as in PCR reactions (tables 1, 2).

\section{Results}

Of the 6 probands ( 2 male, 4 female) subjected to molecular analysis of the APC gene, mutations were detected in $3(50 \%)$. Age at the diagnosis of disease ranged from 27 to 54 years, with a mean of 39 years. All 6 of these probands had more than 100 adenomas in the colon and 
Table 3. Summary of the APC gene sequence changes in this study

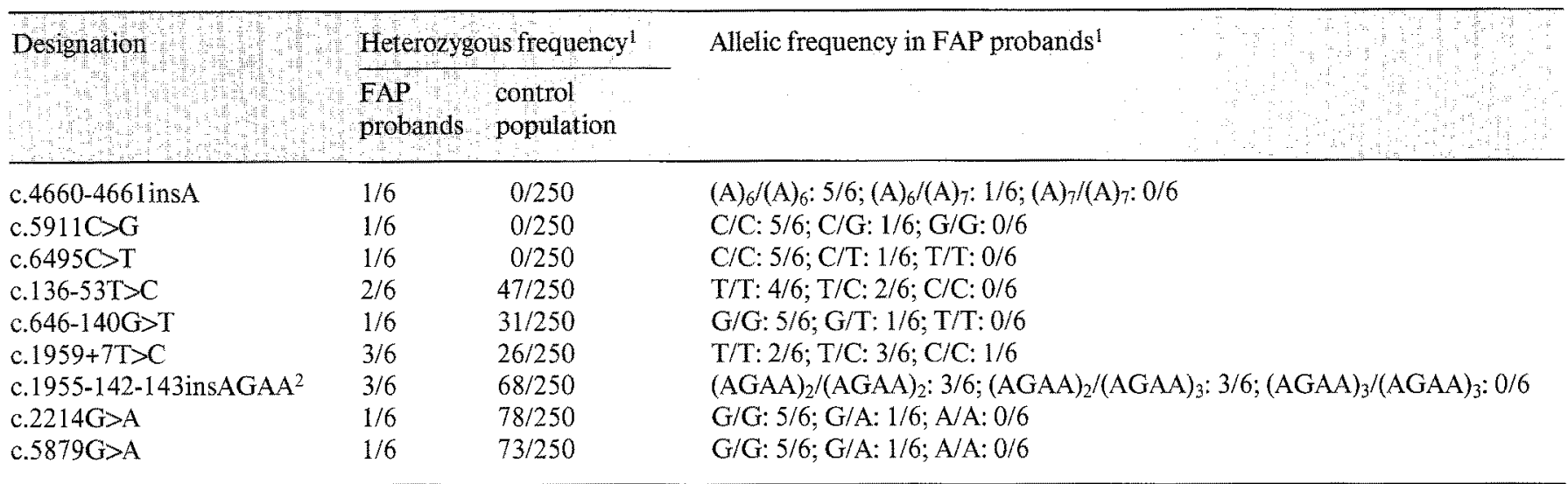

1 As DHPLC detects the presence of heteroduplex DNA, the heterozygous frequency instead of the specific allelic frequency is shown in this table. The allelic frequency in the FAP probands is listed according to the sequencing results.

2 This polymorphic site indicates the changes in the repeat number of the AGAA tandem sequence.

had received total colectomy. Two of them had invasive lesions (rectal cancer in one, transverse colon cancer in the other). As for the extracolonic manifestations, 1 had fundic gland polyposis and another had lipoma on the back. In addition, a third proband had a family member who suffered from oral cancer.

In this study, we used DHPLC as the first screen to identify heterozygous profiles and found 21 heterozygous profiles. Among the 21 heterozygous profiles, 3 had amino acid changes which occurred only in the FAP probands and not in the 250 population controls. These three mutations were all in exon 15 . Two of these mutations were novel, while the third belonged to a category that has been reported as a mutation hot spot in APC. The first novel mutation was at codon 2166 in exon 15 , with a $\mathrm{C}$ to $\mathrm{T}$ transition (CGA $\rightarrow$ TGA; c.6495C $>$ T), resulting in a stop codon (fig. 1a). The second novel mutation we found was at codon 1971 in exon 15 , with a $C$ to $G$ transversion (TCT $\rightarrow$ TGT; c.5911C>G), resulting in an amino acid change from serine to cysteine (fig. 1b). The third mutation involved an A insertion in an -AAAAAA- sequence at codons 1554-1556 (c.4660-4661insA) (fig. 1c), which caused a stop codon downstream (at codon 1558). Another 2 heterozygous profiles had nucleotide changes in the exons (c. $2214 \mathrm{G}>\mathrm{A}$, c. $5879 \mathrm{G}>\mathrm{A}$ ) that were also detected in the control population and were hypothesized to represent polymorphism. Another 9 heterozygous profiles had 4 types of base substitution in the intron sequences that did not affect the splicing sites. No sequence change was identified in the remaining 7 heterozygous profiles detected by DHPLC. The locations and frequencies of these sequence changes are summarized in table 3 . The nomenclature for the description of sequence variations was guided by a new nomenclature system recommended by the Human Genome Variation Society (http://www. hgvs.org/mutnomen/) for a uniform and unequivocal description of sequence variants.

\section{Discussion}

This study is the first report of mutation analysis of the APC gene in Taiwanese. Among the 6 probands subjected to genetic analysis of the $A P C$ gene, 3 mutations (50\%) were detected. Compared with previous studies $[11,17,19,20$, 24,25 ], the mutation rate in this study is similar to those reported for Israelis (50.7\%) and Czechs (45.4\%), but lower than those for Greeks (83\%), Finns (72\%) and others (up to 95\%). The mutation rates in the APC gene vary among different ethnic groups. Further comparison of Chinese ethnic groups from different areas showed that our result in Taiwanese was similar to that from Hong Kong (50\%), but lower than that from Singapore $(68 \%)[5,26]$. In contrast to the Hong Kong report and our study, which included exclusively ethnic Chinese, the study from Singapore included some patients from different ethnic groups. This might explain the discrepancy between the APC mutation rates in Chinese ethnic groups from different areas.

After searching the APC mutation databases (UMD) [31], we found that two of the three mutations that we identified were novel. These two mutations were located at codons 1971 and 2166, which were predicted to be the 

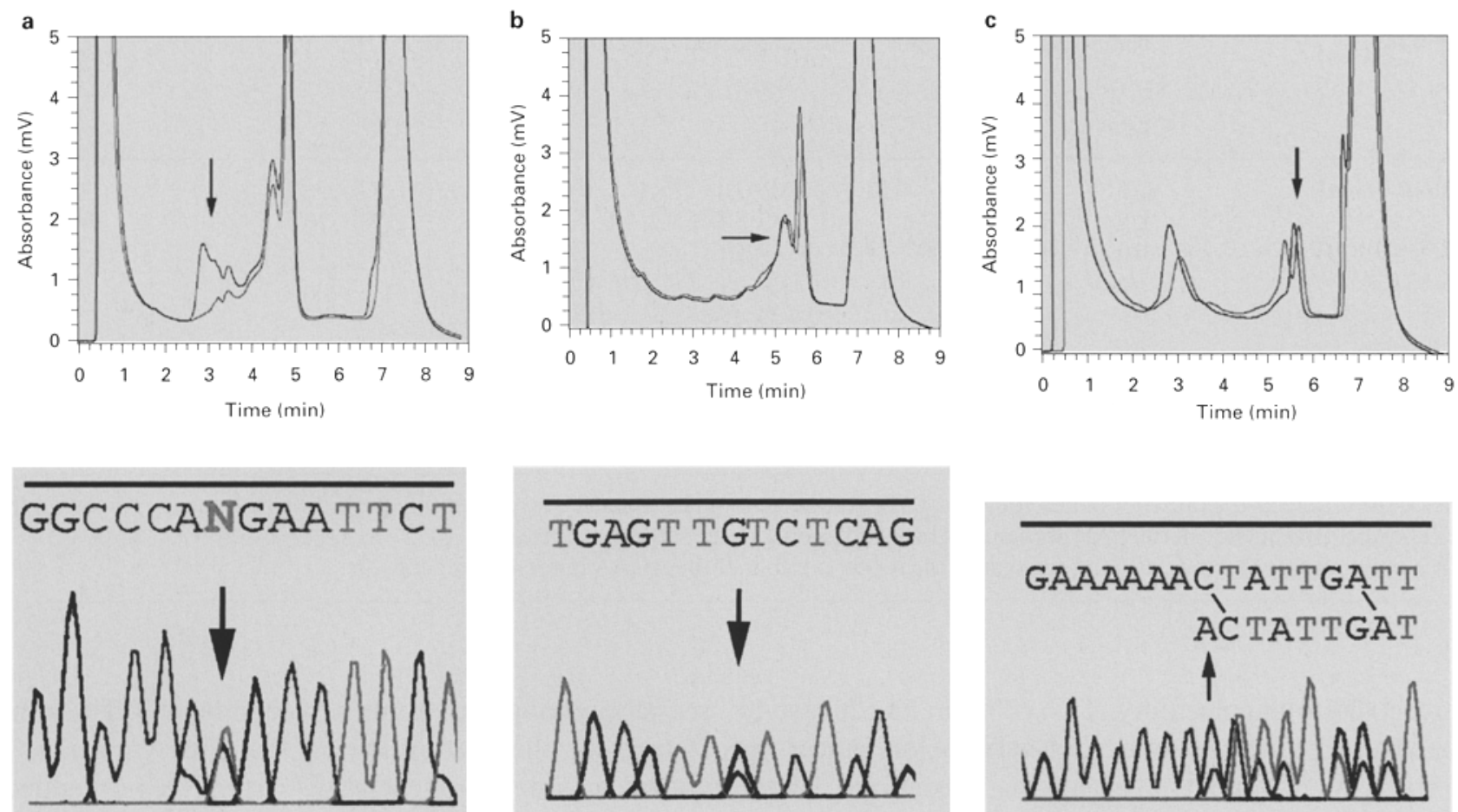

Fig. 1. The APC mutations detected in FAP probands. The upper panels show heterozygous profiles detected by DHPLC. The automatic sequencing results are shown in the lower panels. a The $\mathrm{C}$ to $\mathrm{T}$ transversion (CGA $\rightarrow$ TGA) resulted in a stop codon at codon 2166 in exon 15 (c.6495C $>\mathrm{T}$ ). b The $\mathrm{C}$ to $\mathrm{G}$ transition (TCT $\rightarrow$ TGT) resulted in an amino acid changing from serine to cysteine at codon 1971 in exon 15 (c.5911C > G). c An A insertion at codons 1554-1556 (c.4660-4661 insA) caused a stop codon downstream (codon 1558). binding sites for $\beta$-catenin and axin, respectively [9]. The third mutation was located in an area that was previously reported as a mutation hot spot for APC (codon 1556) $[10,22,23,33]$ and was also predicted to be the binding site for $\beta$-catenin [9]. Mutations in these areas could potentially cause a disruption of interactions between APC and $\beta$-catenin or axin, which in turn would block APC's role as a gatekeeper, hence causing cancer. Whether these mutations will cause incompetence of proteinprotein interaction between APC and $\beta$-catenin or axin remains to be tested. All three mutations were located in exon 15 , which was in accordance with previous reports that exon 15 comprises three fourths of the coding sequence of $A P C$ and is the most common target for both germ line and somatic mutations [9]. Notably, mutation in the most common germ line hot spots (codons 1061 and 1309) [9] was not found in our series.

Since only $50 \%$ of FAP probands have a mutation in the APC gene detected by DHPLC followed by direct nucleotide sequencing methods, we performed another two studies to further clarify the genetic background of Taiwanese FAP probands. First, a protein truncation test was performed to check whether a large fragment deletion existed, such as whole exon deletion, which sometimes escapes DHPLC detection. According to the protein truncation test results, no large deletion or truncated protein was detected (data not shown). Hence, DHPLC seemed to be a sensitive and efficient test for mutation analysis in this study, as has been previously noted $[34,35]$. The second examination we performed was to check the $\mathrm{NH}_{2}-$ terminal regulatory domain of the $\beta$-catenin gene in probands lacking APC mutations. Somatic mutations in the $\mathrm{NH}_{2}$-terminal regulatory domain of $\beta$-catenin were found in $48 \%$ of colorectal cancers lacking APC mutations [32]. PCR using genomic DNA and primers as described previously [32] followed by direct sequencing with internal primers did not find any nucleotide change in the 3 probands. A similar condition had been reported previously $[4,7]$. The genetic cause of the disease in these 3 probands remains to be elucidated. 
Genetic analysis is the basis for early diagnosis and chemoprevention of FAP. For the first time in Taiwan, we were able to identify mutations in Taiwanese FAP patient kindreds and to perform molecular diagnosis. Future studies should enroll more FAP probands to establish the genetic basis of FAP in Taiwanese. To confirm that the mutations are germ line mutations, other members of the FAP probands' families should be included. However, some of the family members were not available at the time of this study. Analysis of other family members is needed. Germ line MYH mutation should also be exam- ined when the family history is compatible with recessive inheritance [30]. If the mutation rate of the APC gene is still low, linkage analysis of the negative mutation screening kindreds should be considered.

\section{Acknowledgements}

This study was supported by grants from the National Science Council, Taipei, Taiwan (NSC89-2315-B-002-028) and the National Taiwan University Hospital (91-M006).

\section{References}

1 Baba S. Familial cancer: Recent advances (in Japanese). Gan To Kagaku Ryoho 26:735-743; 1999.

2 Bisgaard ML, Fenger K, Bulow S, Niebuhr E, Mohr J. Familial adenomatous polyposis (FAP): Frequency, penetrance, and mutation rate. Hum Mutat 3:121-125;1994.

3 Breukel C, Tops C, van Leeuwen C, van der Klift H, Fodde R, Khan PM. AT repeat polymorphism at the D5S122 locus tightly linked to adenomatous polyposis coli (APC). Nucleic Acids Res 19:6665:1991.

4 Cao X, Eu KW, Seow-Choen F, Cheah PY. Germline mutations are frequent in the APC gene but absent in the beta-catenin gene in familial adenomatous polyposis patients. Genes Chromosomes Cancer 25:396-398; 1999.

5 Cao X, Eu KW, Seow-Choen F, Zao Y, Cheah PY. APC mutation and phenotypic spectrum of Singapore familial adenomatous polyposis patients. Eur I Hum Genet 8:42-48;2000.

6 Cruz-Bustillo $D$, Villasana $L$, Llorente $F$, et al. Preliminary results of the molecular diagnosis of familial adenomatous polyposis in Cuban families. Int $\mathrm{J}$ Colorectal Dis 17:344-347; 2002.

7 Dobbie $Z$, Muller $H$. Germline mutations in the beta-catenin gene are not associated with the FAP phenotype without an APC mutation. J Med Genet 36:573-574;1999.

8 Dunlop MG. Screening for large bowel neoplasms in individuals with a family history of colorectal cancer. Br J Surg 79:488-494;1992.

9 Fearnhead NS, Britton MP, Bodmer WF. The ABC of APC. Hum Mol Genet 10:721-733; 2001.

10 Ficari F, Cama A, Valanzano R, et al. APC gene mutations and colorectal adenomatosis in familial adenomatous polyposis. $\mathrm{Br} \mathrm{J}$ Cancer 82:348-353;2000.

11 Gavert N, Yaron $Y$, Naiman T, et al. Molecular analysis of the APC gene in 71 Israel families: 17 novel mutations. Hum Mutat 19:664;2002.

12 Groden J, Thliveris A, Samowitz W, et al. Identification and characterization of the familial adenomatous polyposis coli gene. Cell 66:589$600 ; 1991$.
13 Gryfe R, Swallow C, Bapat B, Redston M, Gallinger $\mathrm{S}$, Couture J. Molecular biology of colorectal cancer. Curr Probl Cancer 21:233-300; 1997.

14 Department of Health, Taiwan. Health and Vital Statistics Taiwan area, ROC, 2001.

15 Hodgson SV, Coonar AS, Hanson PJ, et al. Two cases of $5 \mathrm{q}$ deletions in patients with familial adenomatous polyposis: Possible link with Caroli's disease. J Med Genet 30:369375;1993.

16 Huber CG, Oefner PJ, Bonn GK. High-resolution liquid chromatography of oligonucleotides on nonporous alkylated styrene-divinylbenzene copolymers. Anal Biochem 212:351-358; 1993.

17 Hutter P, Rey-Berthod C, Chappuis PO, et al. Molecular and clinical characteristics in 32 families affected with familial adenomatous polyposis. Hum Mutat 18:550;2001.

18 Kinzler KW, Nilbert MC, Su LK, et al. Identification of FAP locus genes from chromosome 5q21. Science 253:661-665;1991.

19 Kohoutova M, Stekrova J, Jirasek V, Kapras J. APC germline mutations identified in Czech patients with familial adenomatous polyposis. Hum Mutat 19:460-461;2002.

20 Laken SJ, Papadopoulos N, Petersen GM, et al. Analysis of masked mutations in familial adenomatous polyposis. Proc Natl Acad Sci USA 96:2322-2326;1999.

21 Lindgren V, Bryke CR, Ozcelik T, Yang-Feng TL, Francke U. Phenotypic, cytogenetic, and molecular studies of three patients with constitutional deletions of chromosome 5 in the region of the gene for familial adenomatous polyposis. Am J Hum Genet 50:988-997;1992.

22 Matsumoto T, Jida M, Kobori Y, Mizuno M, Nakamura S, Hizawa K. Progressive duodenal adenomatosis in a familial adenomatous polyposis pedigree with APC mutation at codon 1556. Dis Colon Rectum 45:229-233;2002.

23 Matsumoto T, Iida M, Kobori $Y$, et al. Serrated adenoma in familial adenomatous polyposis: Relation to germline APC gene mutation. Gut 50:402-404;2002.

24 Mihalatos M, Danielides I, Belogianni J, et al. Novel mutations of the APC gene in familial adenomatous polyposis in Greek patients. Cancer Genet Cytogenet 141:65-70;2003.
25 Moisio AL, Jarvinen H, Peltomaki P. Genetic and clinical characterisation of familial adenomatous polyposis: A population based study. Gut 50:845-850;2002.

26 Pang CP, Fan DS, Keung JW, et al. Congenital hypertrophy of the retinal pigment epithelium and APC mutations in Chinese with familial adenomatous polyposis. Ophthalmologica 215 : $408-411 ; 2001$.

27 Petersen GM, Boyd PA. Gene tests and counseling for colorectal cancer risk: Lessons from familial polyposis. J Nati Cancer Inst Monogr (17):67-71;1995.

28 Petersen GM, Slack J, Nakamura Y. Screening guidelines and premorbid diagnosis of familial adenomatous polyposis using linkage. Gastroenterology 100:1658-1664;1991.

29 Resta N, Stella A, Susca F, et al. Nine novel APC mutations in Italian FAP patients. Hum Mutat 17:434-435;2001.

30 Sieber OM, Lipton L, Crabtree M, et al. Multiple colorectal adenomas, classic adenomatous polyposis, and germ-line mutations in MYH. N Engl J Med 348:791-799;2003.

31 Soussi T. UMD APC mutation database. Available at http://www umd necker.fr/, 2003.

32 Sparks AB, Morin PJ, Vogelstein B, Kinzler KW. Mutational analysis of the APC/beta-cate$\mathrm{nin} / \mathrm{Tcf}$ pathway in colorectal cancer. Cancer Res 58:1130-1134;1998.

33 Toyooka M, Konishi M, Kikuchi-Yanoshita R, Iwama T, Miyaki M. Somatic mutations of the adenomatous polyposis coli gene in gastroduodenal tumors from patients with familial adenomatous polyposis. Cancer Res 55:31653170;1995.

$34 \mathrm{Wu} \mathrm{G}, \mathrm{Wu}$ W, Hegde M, et al. Detection of sequence variations in the adenomatous polyposis coli (APC) gene using denaturing highperformance liquid chromatography. Genet Test 5:281-290;2001.

35 Young J, Barker M, Fraser L, et al. Mutation searching in colorectal cancer studies: Experience with a denaturing high-pressure liquid chromatography system for exon-by-exon scanning of tumour suppressor genes. Pathology 34: $529-533 ; 2002$. 